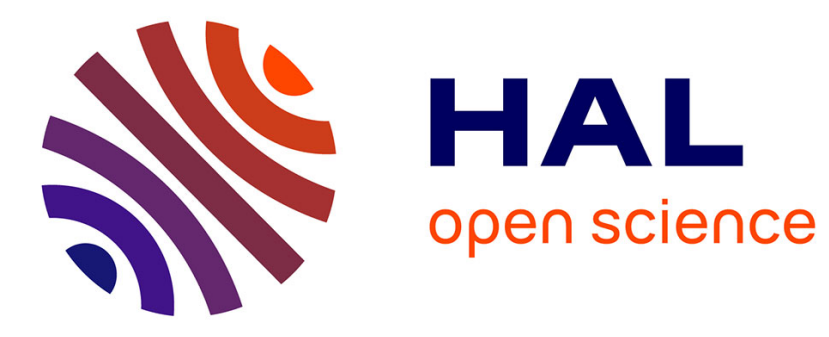

\title{
A Solid Iridium Catalyst for Diastereoselective Hydrogenation
}

Iuliia Romanenko, Louis Jaffeux, Laurent Veyre, Emmanuel Lacôte, Valérie Meille, Chloé Thieuleux

\section{- To cite this version:}

Iuliia Romanenko, Louis Jaffeux, Laurent Veyre, Emmanuel Lacôte, Valérie Meille, et al.. A Solid Iridium Catalyst for Diastereoselective Hydrogenation. Chemistry - A European Journal, 2017, 23 (64), pp.16171-16173. 10.1002/chem.201703872 . hal-01872856

\section{HAL Id: hal-01872856 https://hal.science/hal-01872856}

Submitted on 9 Apr 2019

HAL is a multi-disciplinary open access archive for the deposit and dissemination of scientific research documents, whether they are published or not. The documents may come from teaching and research institutions in France or abroad, or from public or private research centers.
L'archive ouverte pluridisciplinaire HAL, est destinée au dépôt et à la diffusion de documents scientifiques de niveau recherche, publiés ou non, émanant des établissements d'enseignement et de recherche français ou étrangers, des laboratoires publics ou privés. 


\title{
A solid iridium catalyst for diastereoselective hydrogenation
}

\author{
Iuliia Romanenko ${ }^{1}$, Louis Jaffeux ${ }^{2}$, Laurent Veyre ${ }^{1}$, Emmanuel Lacôte ${ }^{1}$, \\ Valérie Meille $^{2}$, and Chloé Thieuleux ${ }^{1}$ \\ ${ }^{1}$ Université de Lyon, Institut de Chimie de Lyon, Laboratoire de Chimie, \\ Catalyse, Polymères et Procédés (UMR 5265 CNRS-Université Lyon \\ 1-CPE Lyon), Équipe Chimie Organométallique de Surface, 43 Bd du 11 \\ Novembre 1918, 69616 Villeurbanne, France. \\ ${ }^{2}$ Université de Lyon, Institut de Chimie de Lyon, Laboratoire de Génie des \\ Procédés Catalytiques (UMR 5285 CNRS-Université Lyon 1-CPE Lyon), \\ 43 Bd du 11 Novembre 1918, 69616 Villeurbanne, France.
}

September 15, 2017

\begin{abstract}
An $\operatorname{Ir}(\mathrm{NHC})$ supported catalyst is used in the selective hydrogenation of terpinen-4-ol to cis p-menthan-4-ol. Its activity, selectivity and stability are compared to those of a homogeneous homologue [ $\mathrm{IrCl}(\mathrm{COD}) \mathrm{MesImPr}]$ and to a commercial $\mathrm{Pd} / \mathrm{C}$. The solid Ir catalyst is much more selective than the Pd catalyst ( 92 vs. $42 \%$ at $80^{\circ} \mathrm{C}$ ) but also more active, more selective and more stable than the iridium complex in solution. For the first time, a supported catalyst shows an enhanced activity with respect to a complex in a diastereoselective hydrogenation reaction.
\end{abstract}

Keywords: diastereoselective hydrogenation; hybrid catalyst; heterogenized complex; iridium

Many iridium complexes are known to be highly active catalysts for the hydrogenation of sterically hindered olefins. For example, $\left[\operatorname{Ir}(\mathrm{COD})(\mathrm{PCy})_{3}(\mathrm{py})\right]^{+}$ $\left(\mathrm{BF}_{4}{ }^{-}\right.$or $\left.\mathrm{PF}_{6}{ }^{-}\right)$often referred as the Crabtree's catalyst, is able to hydrogenate 2,3-dimethyl-but-2-ene at high TOF $\left(4000 h^{-1}\right.$ at $\left.0^{\circ} \mathrm{C}\right)$, when $\mathrm{RhCl}\left(\mathrm{PPh}_{3}\right)_{3}$ and $\mathrm{HRuCl}\left(\mathrm{PPh}_{3}\right)_{3}$ are not active. [1] Besides its high activity, this catalyst was also found to proceed with strongly directing effects. [2] When a strongly ligating group is present on the alkene, then its association to the metal constrains the hydride transfer. This generally results in it being directed selectively onto one side of the double bond. ${ }^{[3]}$ For example, a $99.9 \%$ cis-orientation was found during the hydrogenation of terpinen-4-ol to p-menthan-4-ol (Figure 1). . $^{[2]}$ This orientation was the result of formation of a stable chelating complex of Ir center with the hydroxyl 
group and the double bond of the substrate. The ability of Crabtree's catalyst to transfer hydrogen stereoselectivly was successfully utilized in total synthesis of natural products. $4-11]$ It is worth mentioning that in some cases the use of Crabtree's catalyst was the only possible way to reach targeted molecules. [12, [14]

In sharp contrast, the terpinen-4-ol hydrogenation performed under heterogeneous catalysis led to selectivities ranging from 20 to 53\% depending on the solvent polarity. ${ }^{[15]}$ The authors concluded from their observations that a higher degree of selectivity could not be reached with heterogeneous catalysts because the binding to the $\mathrm{OH}$ group is not sufficiently strong. This means that to achieve high stereoselectivity, one needs to use homogeneous conditions or add a chiral modifier. [16] Nevertheless, extented uses of the $\operatorname{Ir}(\mathrm{I})$ complexes are hampered by the complexity of the systems or by the catalyst low stability as the complex rapidly deactivates in solution via the formation of polynuclear clusters (or nanoparticles).

Immobilizing a homogeneous complex on a solid support may appear as a solution to maintain the properties of the catalyst, but the authors of a recent publication declare: "...homogeneous catalysts are not stable and thus there is little point in immobilizing them. Other problems are lower rates, sometimes lower selectivities and metal leaching".[17]

Some of us recently published the preparation of an $\operatorname{Ir}(\mathrm{NHC})$-based hybrid material where the Ir centers are precisely positioned along the pore channels of a silica framework. ${ }^{[18]}$ This catalyst led to an increased rate and selectivity of the trans-stilbene hydrogenation compared to its molecular Ir analogue.

As the coordination sphere of the surface Ir complex seems to be maintained on the support, we tried to go further than the simple hydrogenation of non-functional olefins $[18]$ and studied the possibility to perform the diastereoselective hydrogenation of terpinen-4-ol to cis p-menthan-4-ol (Figure 1) taking advantage of the capacity of such Ir complexes to direct hydrogenation of hydroxyl-functionalized olefins while maintaining a high diastereoselectivity and avoiding deactivation as encountered with molecular complexes in solution.

The hydrogenation of a solution of terpinen-4-ol in toluene with solid catalyst (M-Ir or Pd/C) was performed in an $300 \mathrm{~mL}$ autoclave at constant hydrogen pressure ( 3 bars) and constant temperature $\left(40,60\right.$ or $\left.80^{\circ} \mathrm{C}\right)$. $\mathrm{Pd} / \mathrm{C}$ was selected to benchmark the typical selectivity of existing heterogeneous catalysts. $\frac{[15[19]}{15}$ The conversion was followed by GC (see Supplementary Informations). A 30mL labreactor was also used to investigate the behavior of the non-immobilized complex, $[\mathrm{IrCl}(\mathrm{COD}) \mathrm{Mes} \mathrm{ImPr}]$, to compare its performance with to that of the heterogenized catalyst. Figure 2 clearly shows that the initial activity of the complex at $40^{\circ} \mathrm{C}$ (white squares) and $80^{\circ} \mathrm{C}$ (white circles) is much lower than that of the heterogenized catalyst (black squares and circles).

During the terpinen-4-ol hydrogenation at $80^{\circ} \mathrm{C}$ with $[\operatorname{IrCl}(\mathrm{COD}) \mathrm{Mes} \operatorname{ImPr}]$, we noticed the formation of a black deposit (Figure 3). TEM and EDX analysis clearly showed it to be Ir particles. This explains the rapid selectivity decrease observed when the hydrogenation is catalyzed by the complex (Figure 4, white curve with triangles). A similar decrease of selectivity vs. conversion was also recorded 
at $40{ }^{\circ} \mathrm{C}$ (white curve with pentagons) albeit it was less rapid at that temperature. Again in contrast, the selectivity remained stable for the hybrid material (Figure 4. black curves).

A decomposition of surface Ir sites may also happen in the case of heterogeneous M-Ir but to obviously a much lower extent, since no loss of activity and selectivity was noticed during the hydrogenation reaction. In order to get more insight into the deactivation process that could occur with the supported catalyst, the latter was kept at $80^{\circ} \mathrm{C}$ under $\mathrm{H}_{2}$ after full conversion of terpinen-4-ol. Some very small Ir nanoparticles (ca. $2 \mathrm{~nm}$ ) were observed by HRTEM at the surface of the silica framework (Figure 5 ) thus showing that Ir may decoordinate under $\mathrm{H}_{2}$ from heterogeneous carbene leading to clusters and nanoparticles.

The initial reaction rate $\left(\mathrm{mol}_{\text {product }} / \mathrm{mol}_{\text {metal }} / \mathrm{h}\right)$ of the heterogeneous iridium catalyst was also compared to that of a commercial Pd/C. It appears that a mol of $\mathrm{Pd}$ is initially 4 times more active than a mol of $\mathrm{Ir}$ at $80^{\circ} \mathrm{C}$ (Figure 6). Nevertheless, the selectivity to cis p-menthan-4-ol is nearly $90 \%$ in the case of $\mathrm{M}$-Ir whereas it only reaches $40 \%$ in the case of Pd. Besides, the kinetic behavior of M-Ir is a zero order with respect to the reactant, whereas an apparent first order can be observed with $\mathrm{Pd}$ (for substrate/metal ratios from 400 to 1500). The zero order can be explained by a strong adsorption of the molecules on the iridium center. ${ }^{[20]}$ The apparent first order rate with $\mathrm{Pd}$ was checked by changing the terpinenol initial concentration. The kinetic order is not due to catalyst deactivation. Note that the results obtained with M-Ir in a large volume autoclave $(300 \mathrm{~mL})$ perfectly match those obtained in a $30 \mathrm{~mL}$ lab-reactor (Figure 6 vs. Figures 2 and 4 ).

Interestingly, the diastereoselectivity was even higher at lower temperatures, reaching $95 \%$ at $40^{\circ} \mathrm{C}$. Nevertheless, the activation energy was very high (ca. $75 \mathrm{~kJ} / \mathrm{mol})$ for M-Ir, leading to a very slow reaction rate at $40^{\circ} \mathrm{C}\left(1 \mathrm{~h}^{-1}\right.$, see Figure 2). The activation energy for $\mathrm{Pd} / \mathrm{C}$ was half that of $\mathrm{M}-\mathrm{Ir}$ (ca. $35 \mathrm{~kJ} / \mathrm{mol}$ ). This is not limited to terpinen-4-ol: a similar kinetic behavior was observed for the hydrogenation of trans-stilbene. In this case a zero order with respect to the reactant for M-Ir and a first order for Pd/C were observed. The activation energy was also twice higher for M-Ir.

In conclusion, we have reported the first example of a highly productive and diastereoselective heterogeneous hydrogenation catalyst which does not rely on additives to proceed. Stereoselectivity was achieved thanks to directed hydride transfer, made possible by the coordination sphere of the catalytic sites. We believe this opens great perspectives for asymmetric heterogeneous catalysis.

\section{References}

[1] R. Crabtree, Accounts of Chemical Research 1979, 12, 331-337.

[2] R. H. Crabtree, M. W. Davis, Organometallics 1983, 2, 681-682.

[3] J. M. Brown, Angewandte Chemie International Edition in English 1987, 26, 190-203. 
[4] M. A. Arnold, K. A. Day, S. G. Durón, D. Y. Gin, Journal of the American Chemical Society 2006, 128, 13255-13260.

[5] P. K. Koech, M. J. Krische, Tetrahedron, New applications of metal catalysis in natural product synthesis 2006, 62, 10594-10602.

[6] W. Qi, M. C. McIntosh, Tetrahedron, Synthetic Advances in Transition MetalCatalyzed Bond-Forming Reactions 2008, 64, 7021-7025.

[7] K. C. Nicolaou, Q. Kang, S. Y. Ng, D. Y. Chen, Journal of the American Chemical Society 2010, 132, 8219-8222.

[8] J. Ramharter, J. Mulzer, European Journal of Organic Chemistry 2012, 2012, 2041-2053.

[9] J. S. Clark, G. Yang, A. P. Osnowski, Organic Letters 2013, 15, 1464-1467.

[10] T. Sakai, A. Fukuta, K. Nakamura, M. Nakano, Y. Mori, The Journal of Organic Chemistry 2016, 81, 3799-3808.

[11] G. Ernouf, J. Brayer, B. Folléas, J. Demoute, C. Meyer, J. Cossy, The Journal of Organic Chemistry 2017, 82, 3965-3975.

[12] S. Hanessian, E. Mainetti, F. Lecomte, Organic Letters 2006, 8, 4047-4049.

[13] T. J. Maimone, J. Shi, S. Ashida, P. S. Baran, Journal of the American Chemical Society 2009, 131, 17066-17067.

[14] A. Shvartsbart, A. B. Smith, Journal of the American Chemical Society 2015, 137, 3510-3519.

[15] R. H. Crabtree, M. W. Davis, The Journal of Organic Chemistry 1986, 51, 2655-2661.

[16] M. Besson, S. Neto, C. Pinel, Chem. Commun. 1998, 1431-1432.

[17] S. Hubner, J. G. de Vries, V. Farina, Advanced Synthesis \& Catalysis 2016, $358,3-25$.

[18] I. Romanenko, D. Gajan, R. Sayah, D. Crozet, E. Jeanneau, C. Lucas, L. Leroux, L. Veyre, A. Lesage, L. Emsley, E. Lacôte, C. Thieuleux, Angewandte Chemie International Edition 2015, 54, 12937-12941.

[19] A. Tungler, G. Fogassy, Journal of Molecular Catalysis A: Chemical, Catlaysis with Supported Palladium Metal at the Turn of the 21st Century 2001, 173, 231-247.

[20] D. Y. Murzin, P. Mäki-Arvela, E. Toukoniitty, T. Salmi, Catalysis Reviews 2005, 47, 175-256. 
<smiles>CC1=CC[C@](O)(C(C)C)CC1</smiles>

$\mathrm{R}+\mathrm{S}$ enantiomers

Terpinen-4-ol

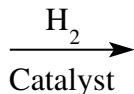<smiles>CC(C)[C@]1(O)CC[C@@H](C)CC1</smiles>

TRANS

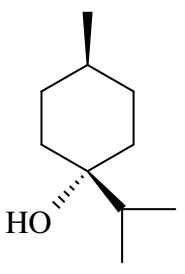

CIS

$\mathrm{p}-$ Menthan-4-ol

1-Isopropyl-4-methyl cyclohexanol

Figure 1: Hydrogenation of terpinen-4-ol.

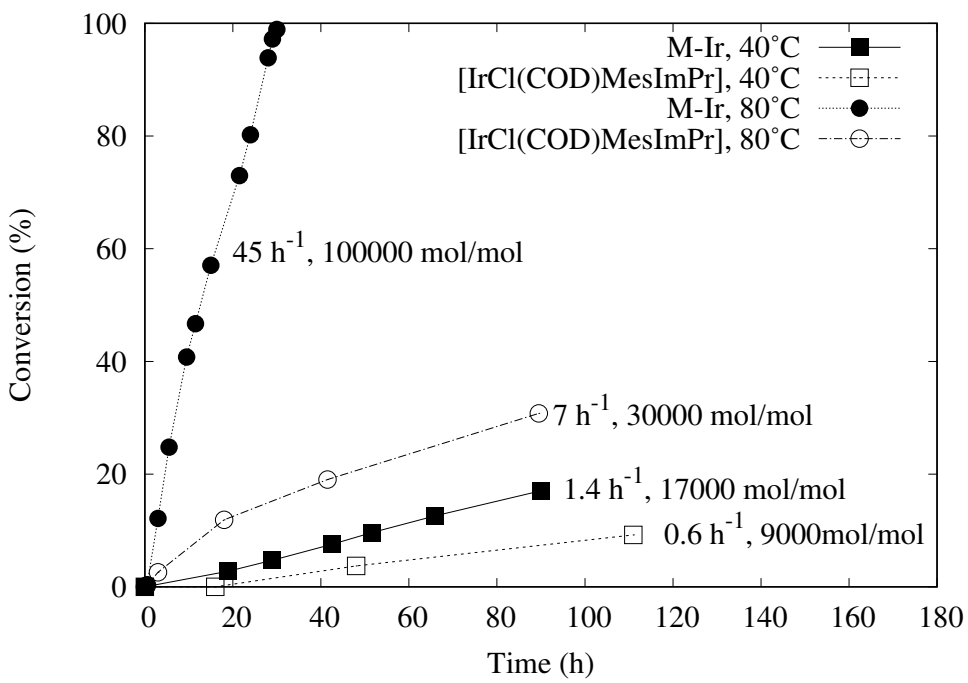

Figure 2: Terpinenol hydrogenation with iridium catalysts at 40 and $80^{\circ} \mathrm{C}, 3$ bars hydrogen, in toluene $(0.47 \mathrm{~mol} / \mathrm{L})$. $30 \mathrm{~mL}$ reactor. Molar ratio substrate/iridium is 1000, initial TOF and final TON provided.
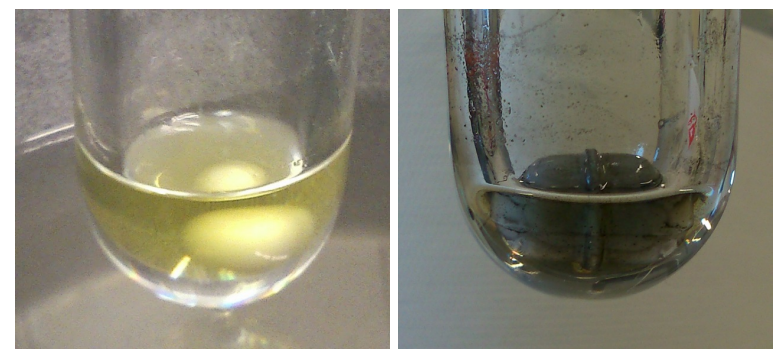

Figure 3: Photos of the [IrCl(CODMesImPr] catalytic solution before (a) and after (b) catalytic reduction of Terpinen-4-ol at $80^{\circ} \mathrm{C}$ with $0.1 \mathrm{~mol} \%$ of catalyst. 


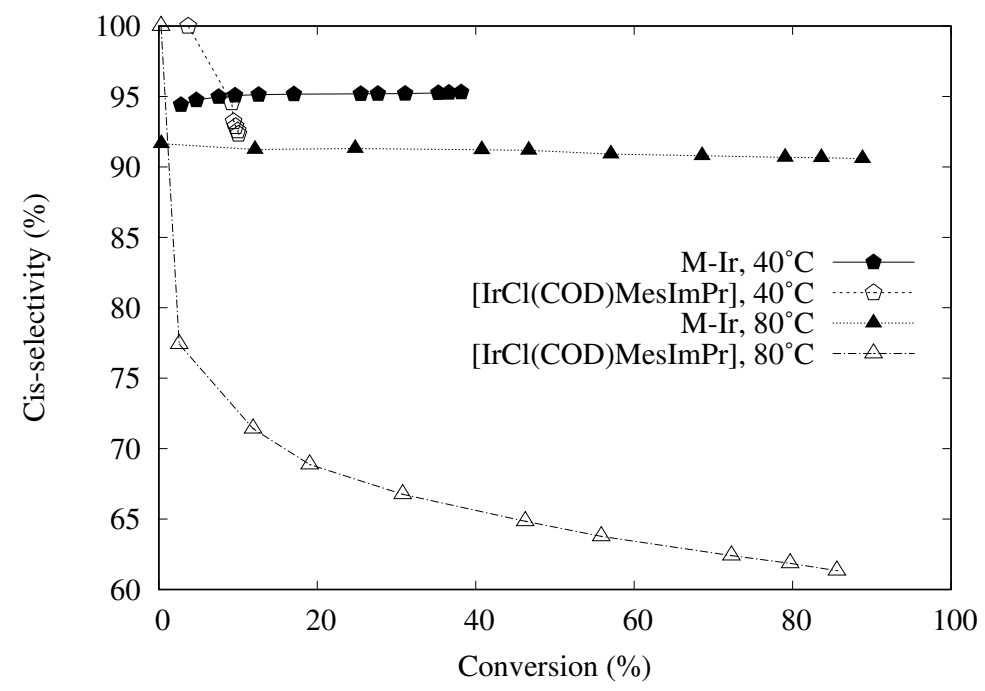

Figure 4: Selectivity vs. conversion during terpinenol hydrogenation at 40 and $80^{\circ} \mathrm{C}, 3$ bars hydrogen, in toluene $(0.47 \mathrm{~mol} / \mathrm{L}) .30 \mathrm{~mL}$ reactor. Molar ratio substrate/iridium is 1000 .

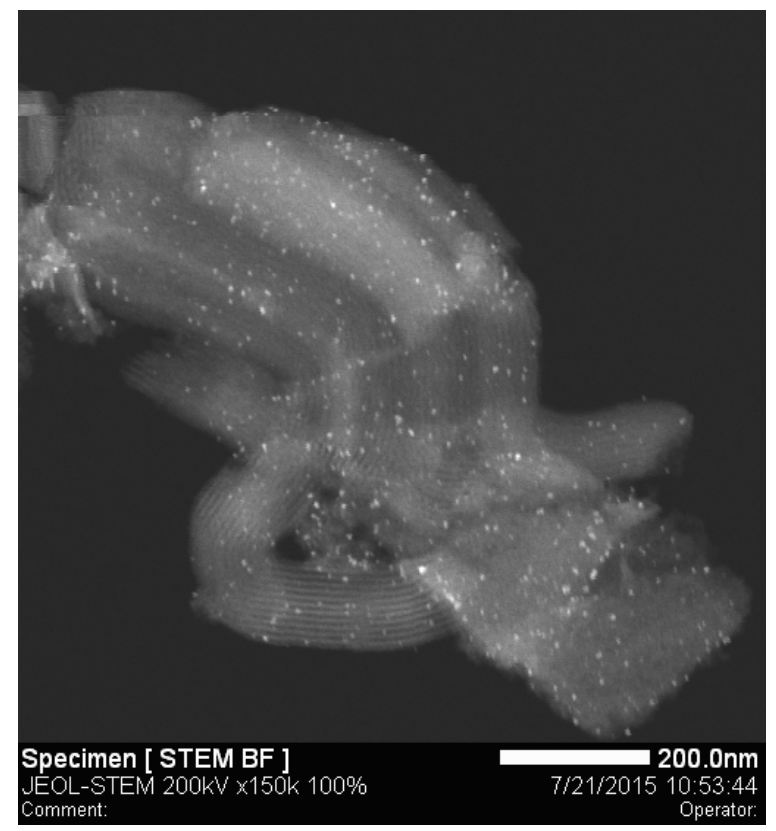

Figure 5: STEM micrographs of the recovered solid after full terpinen-4-ol reduction at $80^{\circ} \mathrm{C}$ with $0.1 \mathrm{~mol} \%$ of $\mathrm{M}-\mathrm{Ir}$ in toluene. 

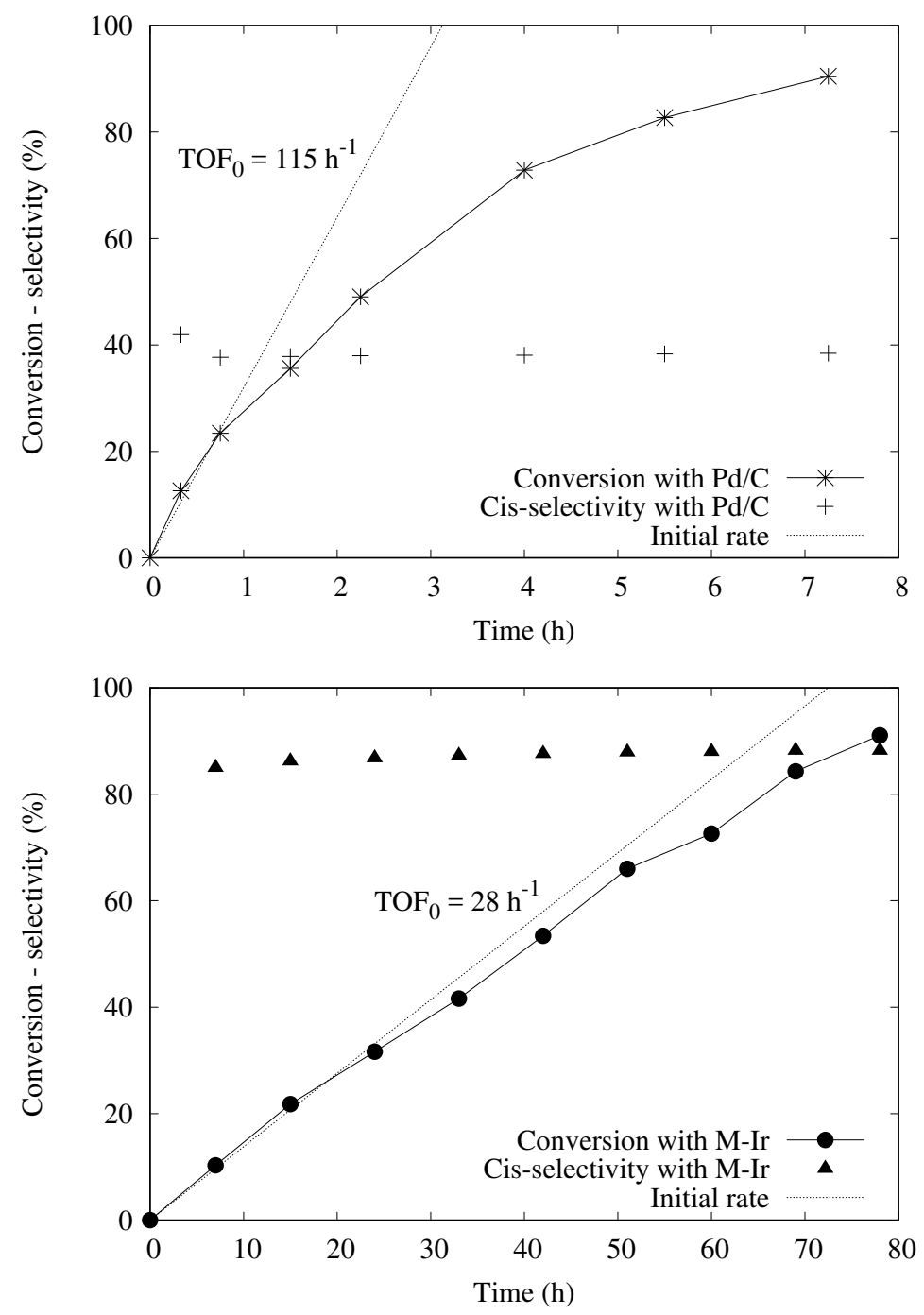

Figure 6: Terpinenol hydrogenation at $80^{\circ} \mathrm{C}, 3$ bars hydrogen, in toluene $(0.63 \mathrm{~mol} / \mathrm{L}) .300 \mathrm{~mL}$ reactor. Molar ratio substrate/metal is 400 for $\mathrm{Pd} / \mathrm{C}$ and 2100 for M-Ir. 